\title{
Automated Primary Health Care Delivery System- The Nigeria Context
}

\author{
Ndubuisi Henry Odikwa ${ }^{1}$, Onwubiko, Davidson ${ }^{2}$, Akwaraonwu, Bright $^{3}$ \\ ${ }^{1}$ Department of Computer Science, Abia State University, Uturu, Abia State, Nigeria \\ ${ }^{2}$ Department of Computer Science, Abia State University, Uturu, Abia State, Nigeria \\ ${ }^{3}$ Department of Computer Science, Michael Okpara University of Agriculture, Abia State, Nigeria
}

\begin{abstract}
Nigeria as a country has a peculiar problem in health care delivery, ranging from disbursement of drugs to the various health centers, prompt payment of health workers salaries and promotions to cumbersome nature of patients seen the medical practitioners to attend to them. This paper focused on the design of primary health care delivery system in Nigeria. The design is made to accommodate both the patients and physicians quests to have a platform where communications are enhanced for effective administration of health care. The automated system is designed with visual sharp programming language and MYSQL that is conveniently accessible to both patients and physicians. The paper also focused on the tracking of drugs from the point of collection to the distribution chain to all the primary health care facilities by using a tracker so to prevent diversion of drugs. The automated system proved to be robust as it carters for the needs of the society in providing affordable, timeless and efficient delivery of health care to the patients.
\end{abstract}

Keywords: Tracking, healthcare, inpatient, outpatient

\section{INTRODUCTION}

$\mathrm{P}$ rimary healthcare is the diagnosis, treatment, and prevention of disease, illness, injury, and other physical and mental impairments in human beings [7]. Primary health care is delivered by practitioners in allied health, dentistry, midwifery (obstetrics), medicine, nursing, optometry, pharmacy, psychology, and other health professions [9]. It refers to the work done in providing primary care, secondary care, and tertiary care, as well as in public health. Access to health care varies across countries, groups, and individuals, largely influenced by social and economic conditions as well as the health policies in place. Countries and jurisdictions have different policies and plans in relation to the personal and population-based health care goals within their societies. Health care systems are organizations established to meet the health needs of target populations. Their exact configuration varies between national and subnational entities. In some countries and jurisdictions, health care planning is distributed among market participants, whereas in others, planning occurs more centrally among governments or other coordinating bodies [10]. In all cases, according to the World Health Organization (WHO), a well-functioning health care system requires a robust financing mechanism; a well-trained and adequately-paid workforce; reliable information on which to base decisions and policies; and well-maintained health facilities and logistics to deliver quality medicines and technologies[11].
The application of information technology in health care is unceasingly evolving as the quality of patient care in contemporary times seems to depend on the timely acquisition and processing of clinical information related to the patient [3]. [5] asserted that a significant paradigm shift has occurred in health care service delivery from an era of physician centeredness to emphasis on quality of patient care, from isolationist practices by caregivers to networking in a global world, and from competition to collaboration among practitioners. In tandem with this trend, improvement in technology and advancement in information systems has been adopted in the health care industry as a business strategy to improve the quality-of-care [4].

\section{LITERATURE REVIEW}

The application of information technology in health care is unceasingly evolving as the quality of patient care in contemporary times seems to depend on the timely acquisition and processing of clinical information related to the patient [2]. Health can be defined as wholeness, soundness or wellness of a person. Primary Health Care", according to the World Health Organization, means essential health care based on practical scientifically sound and socially acceptable methods and technology, made universally accessible to individuals and families in the community through their full participation and at a cost which the country can afford to maintain at every stage of their development in the spirit of self-reliance and self-determination [13]. [12] listed the basic requirements for primary health care as;

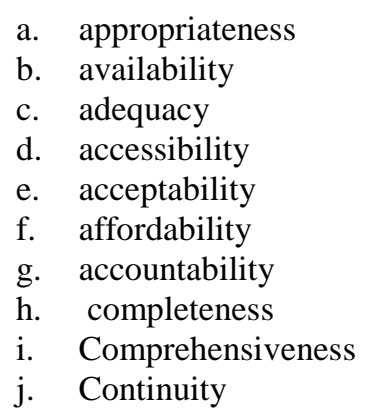

Health care service delivery in Nigeria falls short of international standards resulting from poor state of health care infrastructure, shortage of medical professionals, threat of reemerging infectious diseases, and poor sanitation. Over the last five decades post-independence, growth, and development 
in health care has been dismal. [1][6] Opined the constraints of primary health care in Nigeria as;

1. Lack of political will: Politics have seriously affected the implementation of primary health care delivery in Nigeria. Expansion is very important especially in the rural areas, but what is obtainable is a cankerworm of politicians who take the fund meant for their constituency projects to instituting and reconstructing primary health, diverting such funds into their personal pockets.

2. Inadequate funding. Misappropriation of funds: The government are not keen to provide the necessary funding to primary health care thereby impoverishing the health sector.

Most at times, when the funding are provided by World health Organization, Non-governmental organizations and governments to improve on health care delivery. Such funds released are embezzled by the authorities who are in charge of such projects and eventually sub-standards projects are done, delivery of drugs to the various health care centers are diverted to private hospitals and clinics.

3. Poor inter-sectoral Collaboration and conflicts between the Local governments and States. This has been a paramount problem in health care delivery in Nigeria. The states are the custodian of the funds meant for local governments and only but a miniature of fund is released to primary health cares situated at the local governments. This in turn has created a bottleneck and poor collaboration between the state and local governments.

4. Community Perceptions of Poor Quality of services by Primary health Care Facilities: It is believed that perception influences acceptance, which also influences acceptance. Many especially those in the urban areas and sub-urban have the perception that the facilities in the primary health cares are of substandard and may not meet up with their health requirements, thereby not patronizing the health care delivery facilities in their domains.

5. Inadequate Community Participation: Utilization services is based on community ownership. Communities should guard against external forces such as vandalism of health care facilities in their localities. However, we see that such attitudes are not put up by the host communities thereby allowing some of the primary health care facilities to lie waste.

Definitely, from this context, electronic medical record systems help to improve access to health care in urban, remote suburban areas and ensure improved maintenance of longterm care [8]. Therefore, this paper proposes a better primary health care delivery system that is automated to cater for strong and viable health care system, prompt promotion and welfare of health workers, tracking of drugs delivery and security and full participation of patients in accessing health care facilities in Nigeria.

\section{MATERIALS AND METHODS}

This paper employed the method of primary and secondary data collection to obtain information geared towards finding the problems of primary health care delivery in Nigeria.

\section{Primary Method of Data Collection}

1. Observation

2. Interview

\section{Secondary Method of Data Collection}

1. Online reference materials

\subsection{Data Analysis}

In this research paper, the object oriented programming and analysis design and methodology was employed using the tools such as the sequence diagram shown in figure 2 and the USE CASE diagrams shown in figure 3. The choice of OOADM is for easy emphasis, and to depict the components of the primary health care delivery, as an automated system.

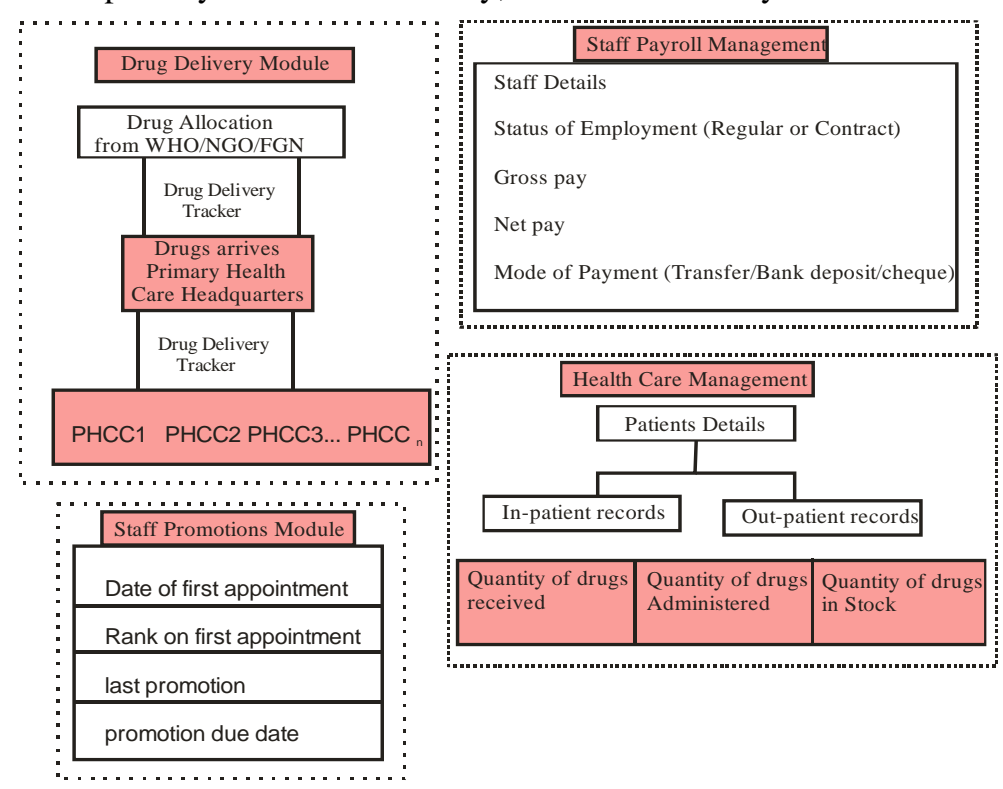

Fig.1: Primary Heath Care Automated System Architectural System

The figure 1 shows the architectural design of the proposed system on primary health care based on four modules; namely: drug delivery, payroll management, promotions and health care management. The drug delivery module has the drug allocation from organizations such as the world health organization and non-governmental organizations (NGO's). the system is made such that right from the delivery of the drugs by the aforementioned organizations, a tracker is deployed to monitor the movement of the drugs from the primary health center headquarters down to the various health centers in all the local government areas of the state designated as PHCC1(Primary Health Care Center 1) to PHCCn (Primary health Care Center n). The payroll module has the staff details which includes the name of staff, sex, marital status, phone numbers, local government area and village. It also comprises of the status of the worker's 
employment whether a contract or regular staff and mode of payment. The promotions module is an automated process that triggers the promotion of a worker based on the recommendation of the head of the department of their various units. Finally, we have the health care management module that tracks the number of in-patients and out-patients in that particular unit and also automated database that determines the quantity of drugs delivered to each center, the quantity of drugs administered to the patients and the quantity that are in the stock.

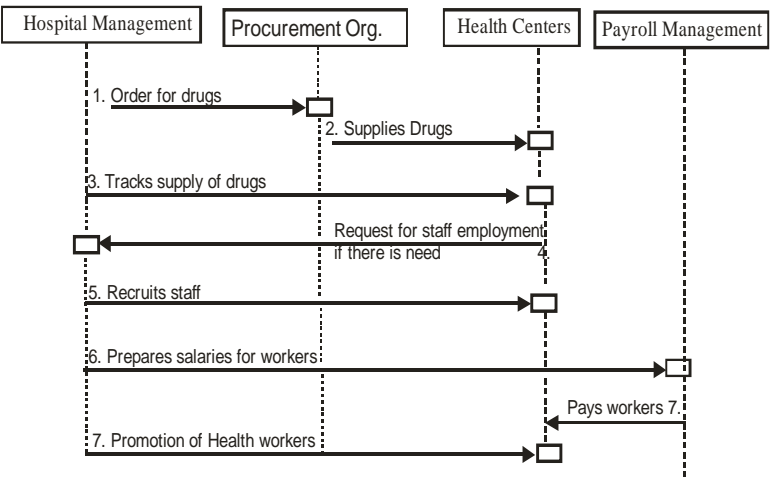

Fig. 2: The Sequence Diagram of the Proposed System

The sequence diagram shown in figure. 2 is used in the analyses of how the data flows from one compartment to the other. The hospital management sees to the ordering of drugs from the WHO/NGO.FGN, tracks the supply of drugs, recruits new staff when the need arises, prepares salaries of the health care staff by the account staff and also see to the promotion of the health workers which will be automated. The procurement organization supplies drugs to the primary health care, while the payroll management pays workers' salaries.

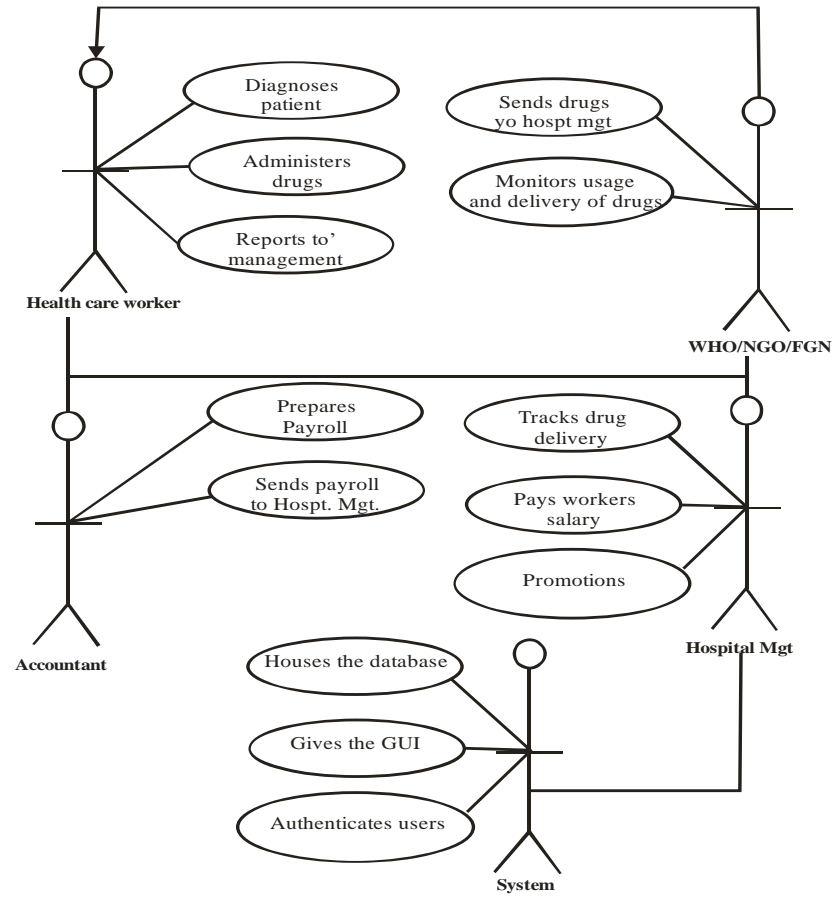

Fig. 3: The USE CASE Diagram of the Proposed System
The USE case diagram is shown in figure 3.3 with the various actors interacting with the system and within the environment. It is a graphical depiction of a user's possible interactions within a system. The actors that interacts in the proposed system are the computer system, health care workers, the hospital management, accountant and the drug providers (WHO,NGO's and FGN). From figure 3.3, the WHO,NGO's and FGN interacts with other actors such as the hospital management board to deliver the necessary drugs, while the hospital management board interacts with all the primary health care centers in the state and the accountant who prepares the monthly salaries, annual leave allowances and promotional allowances. The system which is a very vital part of the interaction automates all the activities of the other actors by hosting the database, monitors and tracks the delivery of drugs, promptly promotes a staff when due with its incremental values and also gives red alert for any retiring staff that is due. The system also authenticates a user of the program during login by checking the details of the user whether the person is an authorized user or an unauthorized user and check whether to grant access or deny access.

\section{DATABASE DESIGN OF THE SYSTEM}

The database design is divided into four modules as shown in tables 1 and 2. the database is designed with SQL which is a database management system.

Table 1: Drug Delivery Module Database

\begin{tabular}{|c|c|c|c|c|}
\hline S/N & $\begin{array}{c}\text { FIELD } \\
\text { NAME }\end{array}$ & $\begin{array}{c}\text { DATA } \\
\text { TYPE }\end{array}$ & SIZE & DESCRIPTION \\
\hline 1 & Drug_Alloc & Varchar & 15 & primary key \\
\hline 2 & Name & Varchar & 25 & Primary key \\
\hline 3 & Tracker_Num & Varchar & 13 & primary key \\
\hline & & & & \\
\hline
\end{tabular}

Table 2: Staff Promotions Database

\begin{tabular}{|c|c|c|c|c|}
\hline S/N & $\begin{array}{c}\text { FIELD } \\
\text { NAME }\end{array}$ & $\begin{array}{c}\text { DATA } \\
\text { TYPE }\end{array}$ & SIZE & DESCRIPTION \\
\hline 1 & DOFA & Varchar & 8 & Candidate key \\
\hline 2 & ROFA & Varchar & 8 & Candidate key \\
\hline 3 & Last_Prom & Varchar & 13 & Candidate key \\
\hline 4 & $\begin{array}{c}\text { Prom_due } \\
\text { date }\end{array}$ & Varchar & 10 & Candidate key \\
\hline & & & & \\
\hline
\end{tabular}

\section{RESULT AND DISCUSSION}

The interface design is very important for any application. The interface design describes how the software communicated with humans who use it. Below are some screenshots of the working system; (Doctor's portal, Admin portal, user's portal, managing patients, adding and removing patients, add and remove doctors, booking appointments, doctor's prescriptions etc.) 
The background page showing the three modules (patients, doctors, admin). Anyone with access or logins, can login to each respective module from this page.

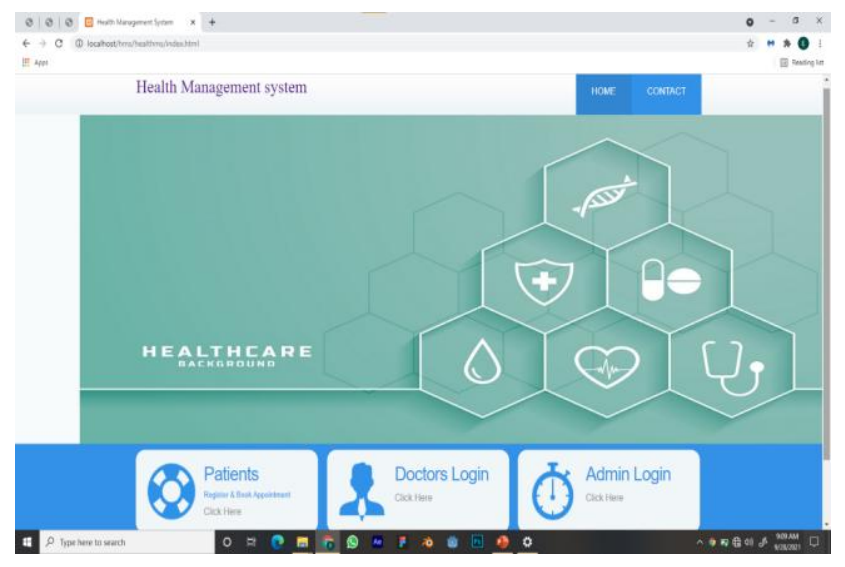

FIG 4: Home Page

The home page depicted in figure 4 is the totality of the primary health care automated system which is peculiar

o solving the intricate problems of health care delivery in Nigerian health care system. The system has the patient's page, the doctors page and the admin page. More figures shown depict how the other interfaces work in collaboration with each other to achieve the desired goal of effective and efficient primary health care delivery.

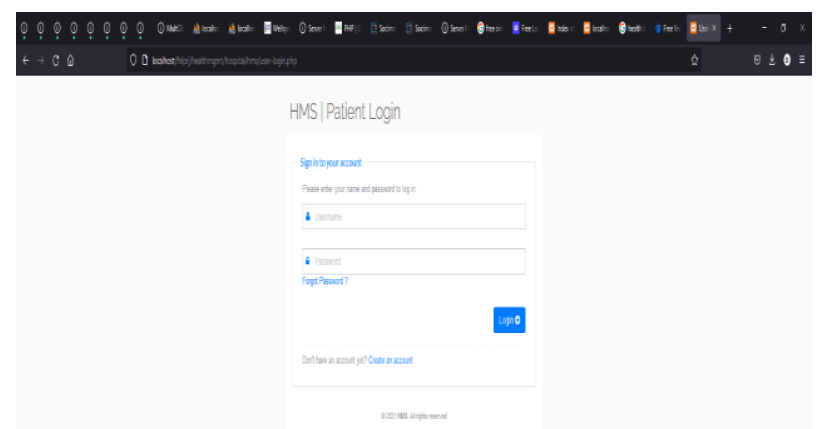

Fig. 5: Patient Login

Here in figure 5, the patient inputs his/her username and password to enable the patient access to the system.

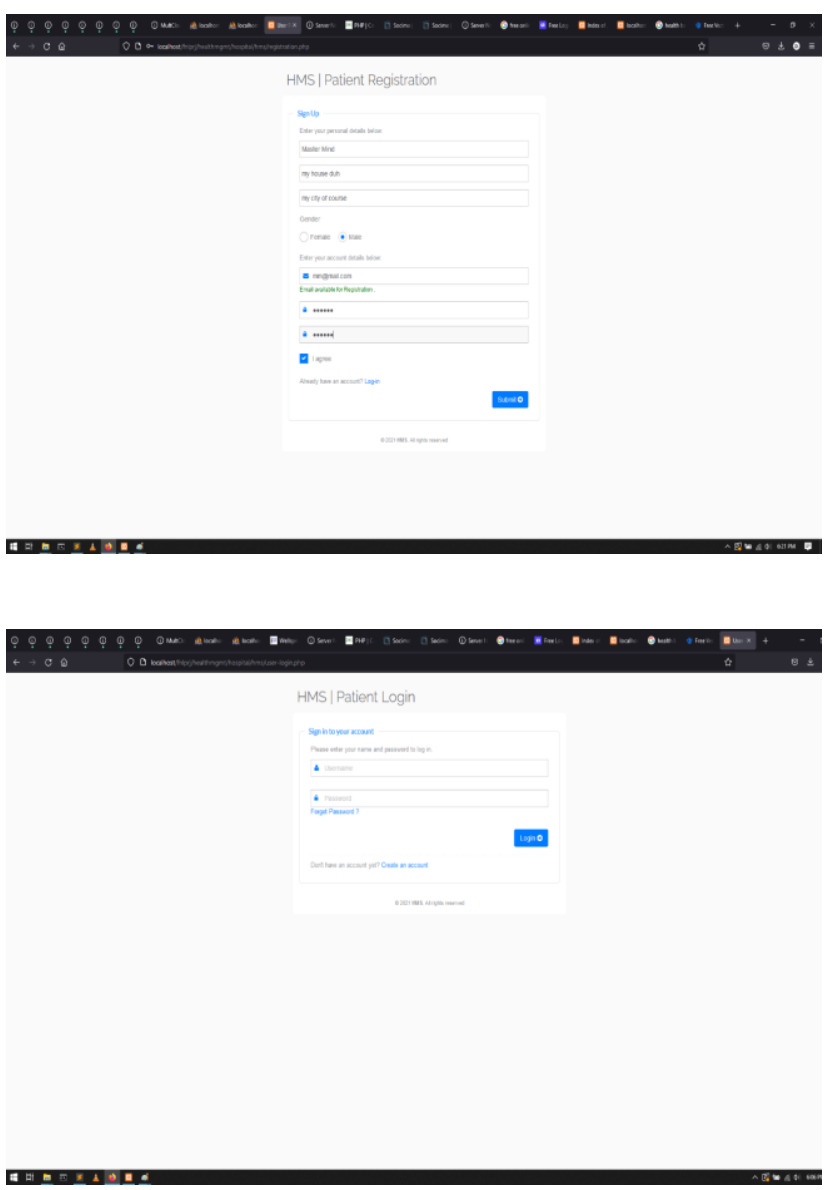

Fig 6: Patient Registration

This is the case of a new patient, new to the hospital system, inputting his/her details, so as the

doctor or admin can add them as their official patient Here, the patient inputs his/her username and password in order to enable the patient access to the system as shown in figure 6 at any time he/she wishes.

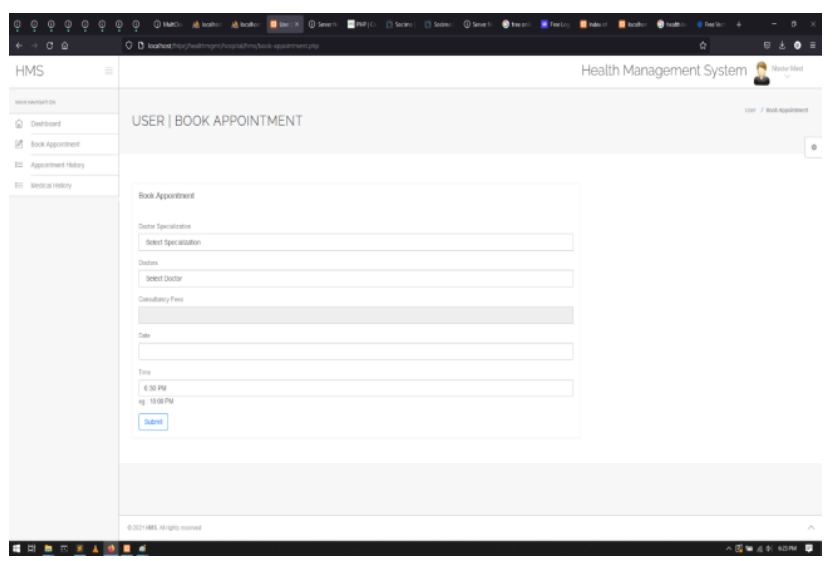

Fig 7 Book Appointment Page 
In figure 7 a patient whose registration is successful will gave direct access to the page where he/she can book appointment with the doctor through the book an appointment depending on their time schedule and availability of the doctor in question. If a doctor is available within a time frame, he can approve the booking or reschedule the booking. This makes it convenient to both the doctor and the patient.

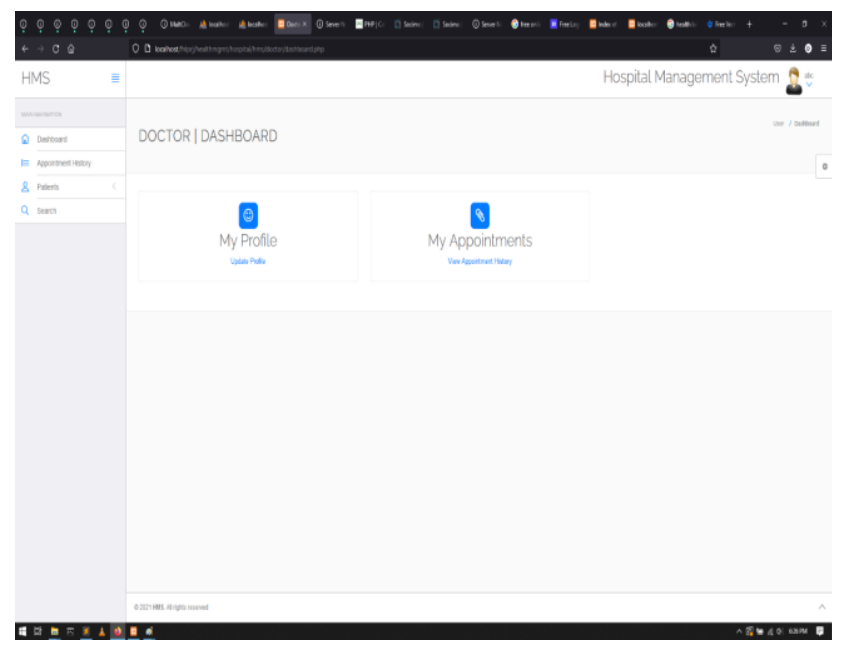

Fig 8 Doctor's Portal

This is basically the doctor's dashboard, showing his/her profile, pending and also cancelled appointments, patients as shown in figure 8

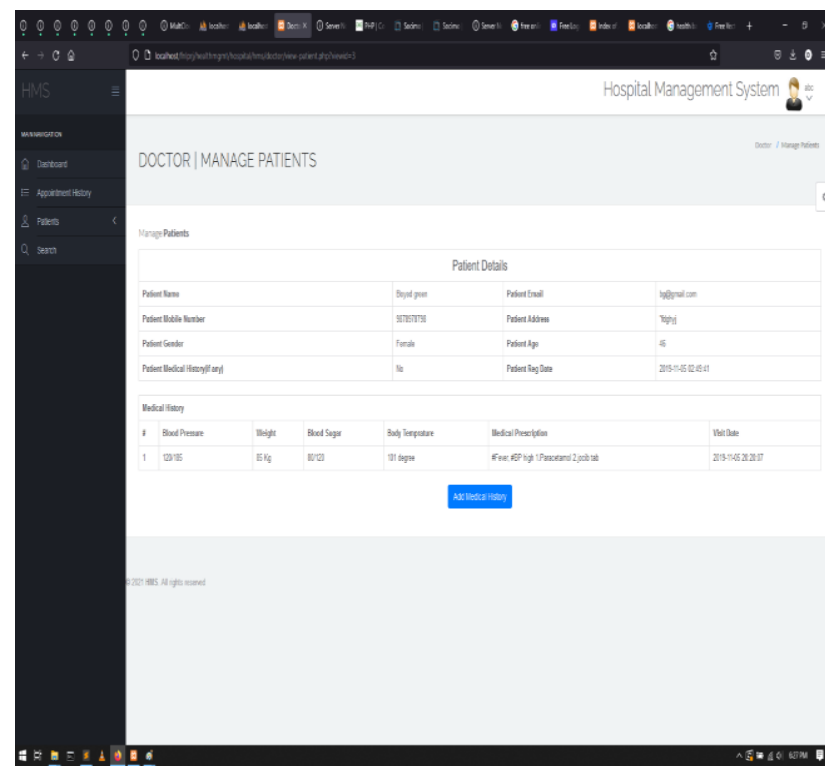

Fig 9: Doctor (Manage Patients)

The figure 9 shows a particular doctor's patient, with all his/her health history details. The doctor may decide to add, edit or remove a patient as the case may be.

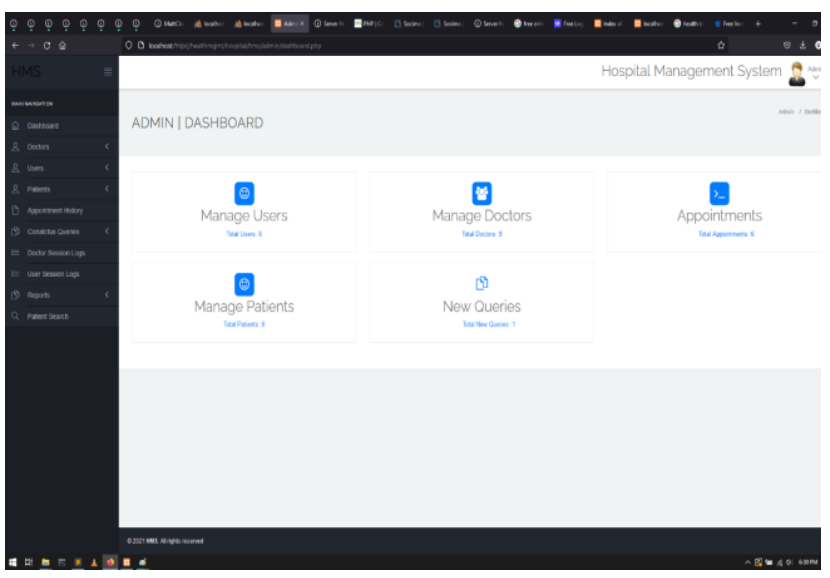

Fig 10 Admin's Portal

This is basically the admin's dashboard, showing his/her profile, appointments, patients, users, queries. The admin monitors the whole activities of the primary health care system as shown in figure 10, which includes the doctor's activities, patient's prescriptions etc.

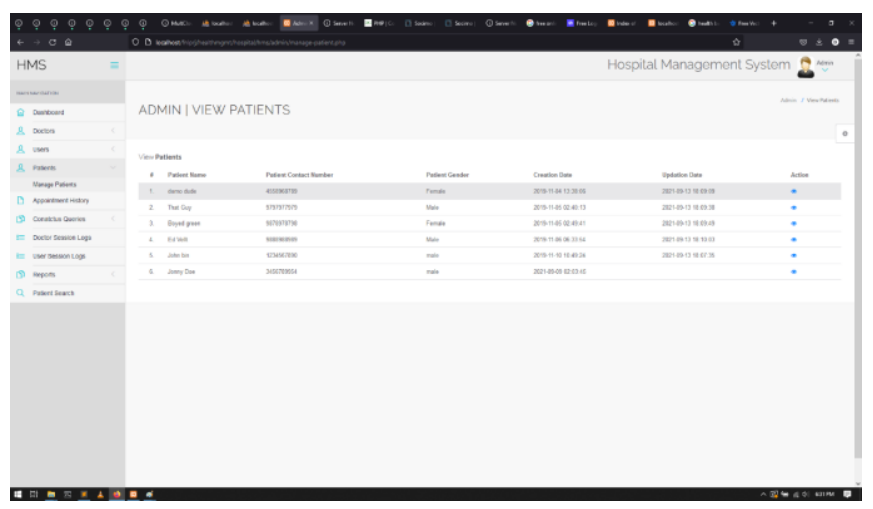

Fig 11 Admin ( View Patients)

From the admin portal, a glance at the total patients registered in the hospital with their respective details as registered is shown in figure 11 .

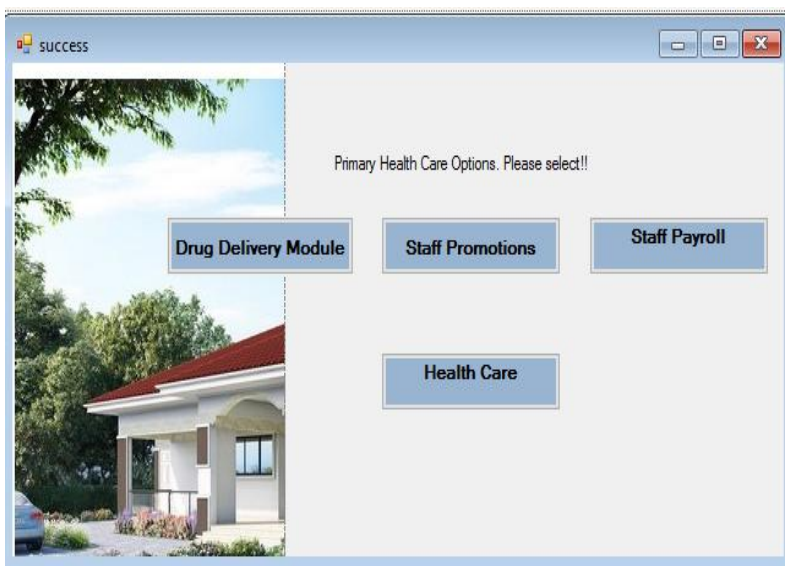

Fig 12: The Primary Health Care Option Screen 
The figure 12 shows the modules for the drug delivery, staff promotions, staff payroll and health care delivery. By clicking or selecting on the modules takes the user to the appropriate module within the system.

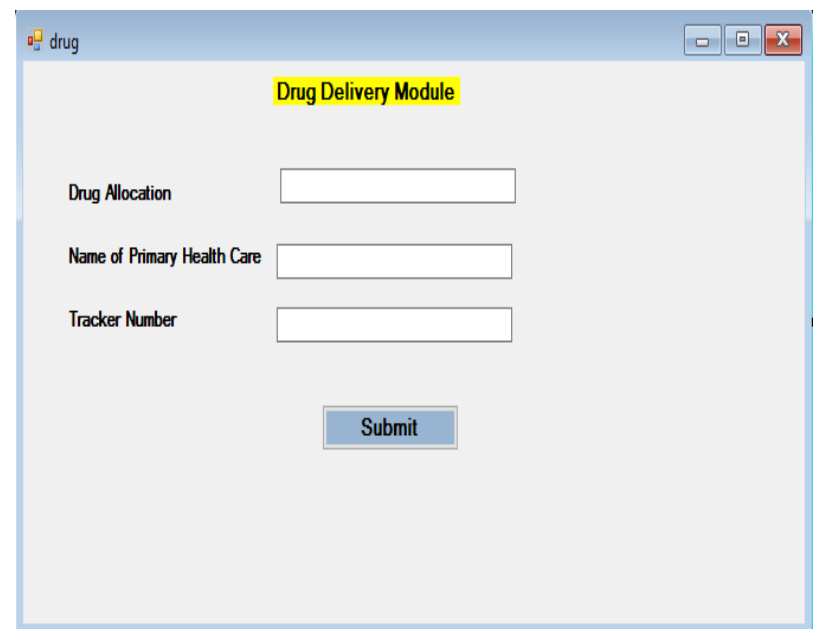

Fig. 13: Drug Delivery Module

To deliver drugs so that it will not get to the wrong hands and to ensure that prompt delivery of drugs is ensured, figure 13 is a module that does that. The drug delivery section has the quantity of drugs allocated for each of the primary health care centers, the name of the health care center and the tracker number for the drugs. With the tracker number, if drugs are found outside the confide of the primary health care centers the health worker in-charge will be queried.

\section{CONCLUSION}

A properly computerized system can save time and money. It improves the business operation and gives the power to access and manipulate vital information quickly and efficiently. This research has been worthwhile as the main aim, which was inefficient and delay of manual system, and unavailability of backup of data and security of patient's information, poor welfare of health workers, delay in salaries and promotions among others have been achieved. Moreover, the research paper enhances data security in primary health care systems because the new system ensures data authenticity, accuracy, and availability any time and in a fast and efficient way. The computerized system is therefore a great advantage to any health care delivery system in Nigeria in general and specifically the Medical Record Department in primary health care centers which till date operates a manual system of record keeping.

\section{REFERENCES}

[1] Aloneghena I, Aigbiromelen A.O, Abejega C, and Eboreime E. (2014). PrimaryHhealth Care in Nigeria: Strategies and onstraints in implementation. International Journal of Community Research. , 3(3), 74-79.

[2] Bailey, N. (2017). A study of queues and appointment systems in hospital outpatient departments, with Special reference to waiting times. Journal of the Royal Statistical Society, 2(14), 185-199.

[3] Bailey, N. (2018). Queuing for medical care. Journal of Applied Statistics 3, 137-145.

[4] Blanco W, M. and Pike, M. (2016). Appointment systems in Outpatients'Clinics and the Effect of Patients' Unpunctuality. Medical Care 2, 133-145.

[5] Brahimi, M and Worthington, D. (2016). Queueing Models for Out-patient Appointment Systems: A Case Study of Italian Hospitals. Journal of the Operational Research Society 9(42), 733746.

[6] Cayirli, T and Veral, E. (2019). Outpatient scheduling in health care: A review of literature. Production and Operations $\begin{array}{llr}\text { Management } & \text { Society } & \text { 4(12), }\end{array}$ 549.http://en.wikipedia.org/hospital information, "hospital information system." Retrieved 12th, December 2021.

[7] Cayirli, T, E. Veral, L and H. Rosen. (2014). Assessment of patient classification in appointment systems. $1^{\text {st }}$ Conference of the POMS College of Service Operations, New York, NY, USA.

[8] Cayirli, T, E. Veral, and H. Rosen. (2006). Designing appointment scheduling systems for ambulatory care services. Health Care Management Science. 3 (4), 47-58.

[9] Chen, R. and L. Robinson. (2005). Scheduling Doctor's Appointments with Unpunctual Patient Arrivals. Working paper, Davis Graduate School of Management, University of California, USA.

[10] Clague, J., P. Reed, J. Barlow, R. Rada, M. Clarke, and R. Edwards. (2015). Improving Outpatient Clinic Efficiency using Computer Simulation. International Journal of Health Care Quality Assurances. 4(10), 43-49.

[11] Cholewka, E. (2016). Management Information System Medical condition dictionary (2010-2011). Retrieved from www.medicondition.net. December, 5, 2021.

[12] Gujirat, P. (2013). Primary Health Concept. Indian Association of Preventive and Social Medicine: Post Graduate certificate course in health system and management. 12-23.

[13] Olofin, O. (2016). Fundamental Concepts of Primary Healthcare Delivery System in Nigeria. Research gate. 1-28. 